Rev. Adm. Saúde Vol. 17, № 69, Out. - Dez. 2017

http://dx.doi.org/10.23973/ras.69.51

ARTIGO ORIGINAL

\title{
Avaliação das posturas dos trabalhadores de uma indústria alimentícia e suas possíveis incidências para LER/DORT
}

Evaluation of workers' posts in a food industry and its possible implications for RSI / WRMD

Josiane Aparecida Cardoso de Souza1, Mauro Lucio Mazini Filho², Antonio Marcos de Almeida ${ }^{3}$, Gabriela Rezende de Oliveira Venturini ${ }^{4}$, Fernando Capobiango Pereira ${ }^{5}$, Felipe José Aidar Martins ${ }^{6}$

\author{
1. Engenheira de produção pelas Faculdades Integradas de Cataguases \\ 2. Doutor em educação física pelas Faculdades Sudamérica \\ 3. Educador físico pela Universidade Federal de Juiz de Fora \\ 3. Educador físico pela Universidade Federal de Juiz de Fora \\ 4. Educador físico pelas Faculdades Sudamérica \\ 5. Educador físico pela Universidade Trás os Montes e Alto D'ouro
}

\section{RESUMO}

O objetivo deste trabalho foi observar se as posturas adotadas pelos funcionários de uma indústria de produtos alimentícios, da cidade de Cataguases-MG, podem ou não acarretar LER/DORT e, através desta, sugerir intervenções para uma melhora da qualidade de vida no trabalho. Foram entrevistados oito funcionários, onde se aplicou um questionário. Mesmo a empresa estudada sendo de pequeno porte foi possível detectar falhas nos postos de trabalho e na organização do trabalho e que com pequenas como implantação da ginástica laboral, pausas para descanso e o uso do banco semi-sentado para a prevenção de patologias como as LER/DORT.

Palavras-chave: LER/DORT; avaliação postural; ergonomia.

\section{ABSTRACT}

The objective of this study was to observe whether the postures adopted by employees of a food industry in the city of Cataguases-MG may or may not lead to 
RSI / WRMD and, through this, suggest interventions to improve the quality of life at work. Eight employees were interviewed, where a questionnaire was applied. Even the company studied being small it was possible to detect job failures and work organization and with small ones such as the implantation of work gymnastics, rest breaks and the use of the semi-seated bank for the prevention of pathologies such as $R S I / W R M D$.

Keywords: RSI/ WRMD; postural assessment; ergonomics.

\section{INTRODUÇÃO}

A ergonomia é uma ciência multidisciplinar com a base formada por várias outras ciências entre elas, antropométrica, biomecânica, anatomia, fisiologia e outras, na qual abrange o estudo das unidades de trabalho, onde se preocupa com o funcionamento global de uma equipe inserida na distribuição de tarefas entre o homem e máquinas, ou, tão somente, da mecanização das tarefas. A análise dos postos de trabalho estuda a essência da atuação do trabalhador, enfatizando a qualificação da tarefa, da postura e das exigências físicas e psicológicas, em uma abordagem ergonômica. [1]

De acordo com a Norma Regulamentadora 17 (NR 17), que trata da ergonomia, destaca-se que nas atividades que exijam sobrecarga muscular estática ou dinâmica do pescoço, ombros, dorso e membros superiores e inferiores, e a partir da análise ergonômica do trabalho, deve ser observado o seguinte.

a) Todo e qualquer sistema de avaliação de desempenho para efeito de remuneração e vantagens de qualquer espécie deve levar em consideração as repercussões sobre a saúde dos trabalhadores;

b) Devem ser incluídas pausas para descanso;

c) Quando do retorno do trabalho, após qualquer tipo de afastamento igual ou superior a 15 (quinze) dias, a exigência de produção deverá permitir um retorno gradativo aos níveis de produção vigentes na época anterior ao afastamento. Ainda em relação a esta normatização destacam-se inúmeras outras considerações que devem ser levadas em consideração com intuito de deixar os trabalhadores em seus postos de trabalho com maior conforto possível e consequentemente rendendo mais para suas funções e consequentemente se afastando dos riscos das doenças ocupacionais. Dentre estas também se destacam os ajustes nos mobiliários, a iluminação adequada e o afastamento ao máximo nos ruídos que possam interferir na concentração para o trabalho e na produtividade. [2]

Vários fatores associados ao trabalho concorrem para a ocorrência de Lesão Por Esforço Repetitivo (LER) e Distúrbios Osteomuscular Relacionado ao Trabalho (DORT) como a repetitividade de movimentos, a manutenção de posturas inadequadas, o esforço físico com cargas exageradas, a invariabilidade de tarefas, a 
pressão mecânica sobre determinados segmentos do corpo, o trabalho muscular estático, impactos e vibrações. A intensificação do ritmo, da jornada, da pressão por produção e a perda acentuada do controle sobre o processo de trabalho por parte dos trabalhadores (fatores relacionados à organização do trabalho), têm sido apontados como os principais determinantes para a disseminação da doença. [3]

Para diminuir estas possíveis incidências em doenças ocupacionais e fazer com que o rendimento profissional seja bastante produtivo, algumas empresas têm adotado a chamada ergonomia participativa em algumas ocasiões, pois ninguém melhor que 0 próprio funcionário para mostrar o que pode e precisa ser modificado e melhorado em seu próprio posto de trabalho. A partir desta premissa, surgem algumas sugestões para melhoria do rendimento e qualidade de trabalho e vida dos trabalhadores onde as principais recomendações são a intervenção relacionada às modificações nos mobiliários e ajustes dos postos de trabalho propriamente dito e a implantação da ginástica laboral que pode ser definida como exercícios praticados dentro da própria empresa que compreende exercícios específicos de alongamento, de fortalecimento muscular, de coordenação motora, de relaxamento e dinâmicas de grupo que são realizadas em diferentes setores ou departamentos da empresa, tendo como objetivo principal prevenir e diminuir os casos de LER/DORT [4], além de buscar aumentar inúmeros benefícios biopsicossociais que tanto melhorarão a imagem da empresa a nível organizacional quanto junto a seus funcionários, buscando um melhor ambiente de trabalho e aumento da produtividade.

No Brasil, a síndrome de origem ocupacional foi reconhecida pelo Ministério da Previdência Social como Lesões por Esforços Repetitivos (LER), por meio da Norma Técnica de Avaliação de Incapacidade. Em 1997, com revisão desta norma foi introduzida a expressão DORT [5]. A instrução normativa do Instituto Nacional de Seguridade Social (INSS) usa a expressão LER/DORT, estabelecendo um conceito da síndrome, declarando que ela não se origina exclusivamente de movimentos repetitivos, podendo ocorrer pela permanência prolongada dos segmentos corporais em determinadas posições, assim como a necessidade de concentração e atenção do trabalhador para realização das atividades laborais e a pressão imposta pela organização do trabalho [6]. A capacidade laboral representa o quanto o individuo está bem no momento e em um futuro próximo, e o quanto está apto para realizar suas atividades com relação às exigências do trabalho, à saúde e aos recursos mentais. Ela está diretamente relacionada ao bem-estar físico e mental do trabalhador ao modo como ele pode desenvolver sua tarefa da melhor maneira possível. O estilo de vida da pessoa, bem como o ambiente de trabalho são fatores que afetam diretamente a capacidade laboral [7], por isso deve sempre buscar adaptar o trabalho ao homem e não ao contrário, sendo esse o principal objetivo da ergonomia e associar isto a prática de exercícios físicos regulares, afastando os trabalhadores da hipocinesia favorecendo os mesmos a adquirirem uma saúde mais satisfatória o que fará os mesmos consequentemente mais preparados para suas atividades laborais.

Visto isto, o objetivo do presente estudo foi observar se as posturas adotadas pelos funcionários, de uma indústria de produtos alimentícios da cidade de CataguasesMG, podem ou não acarretar LER/DORT e sugerir intervenções para uma melhora da qualidade de vida no trabalho. 


\section{METODOLOGIA}

O presente estudo foi realizado em uma empresa de produtos alimentícios na cidade de Cataguases, composta por 12 funcionários, como se tratou de um estudo voluntário, apenas 08 funcionários participaram do mesmo. A amostra foi composta por 04 do sexo masculino e 04 do sexo feminino, onde toda população estudada apresentava idade média de $31 \pm 4,24$ anos. A função destes trabalhadores se pautava na confecção de biscoitos manualmente e por maquinário. Os dados foram coletados através de um questionário semiestruturado fechado e adaptado do questionário original de Couto (checklist) com questões referentes às possíveis prevalências de casualidades da patologia, sendo retiradas 06 questões para discussão, por serem as mesmas consideradas pelos autores desse estudo como de maior relevância para o surgimento de LER/DORT. Após, uma previa reunião com os empresários, foi acordado que esse questionário fosse respondido individualmente pelos funcionários em suas próprias residências, sendo assim, em um primeiro momento, foram esclarecidas todas as dúvidas com a realização de uma leitura de todo questionário, entretanto, caso houvesse outras dúvidas posteriores, estas seriam esclarecidas quanto à devolução do presente questionário dentro de 24 horas, junto dos responsáveis legais pela pesquisa, fato esse que se fez desnecessário, pois todos retornaram com seus questionários devidamente preenchidos.

Vale ressaltar que num primeiro momento onde foram apresentados os propósitos e objetivos do estudo, foi solicitado a todos os participantes que lessem e assinassem um Termo de Consentimento Livre e Esclarecido (TCLE) respeitando assim os cuidados éticos legais de acordo com as normas do Conselho Nacional de Saúde 196/96. Foram informados ainda aos participantes que este estudo tratava-se de um trabalho voluntário que não acarretaria nenhuma remuneração extra para a participação do mesmo e que nenhum deles era obrigado a participar.

\section{Estatísticas utilizadas}

Foram utilizados os métodos de estatística descritiva que possibilitam caracterizar o universo amostral, sob os seus aspectos de distribuição de frequência, quando se mensuram dados discretos (média e desvio padrão).

O emprego de técnicas da estatística descritiva visará caracterizar o universo amostral pesquisado. Para a descrição dos dados coletados foram utilizadas medidas de localização, (THOMAS; NELSON; SILVERMAN, 2007). A análise estatística foi conduzida utilizando o software SPSS 17.0 para Windows.

\section{RESULTADOS E DISCUSSÃO}

As DORT e LER surgiram durante a revolução industrial, quando ocorreram grandes mudanças trabalhistas como divisão de trabalho e aumento da carga horária. $\mathrm{O}$ importante naquela época era o aumento da produtividade sem se preocupar com a saúde dos trabalhadores e nem com o ambiente de trabalho. Atualmente a alta 
incidência das doenças osteomusculares, está associada com a tecnologia e informatização, forçando os trabalhadores a permanecerem em um trabalho estático e repetitivo durante várias horas ao dia; gerando assim a fadiga muscular e grande desconforto físico e mental [8].

Tabela 1. Questões referentes a sobrecargas dos membros superiores no trabalho

\begin{tabular}{lrr}
\hline QUESTÕES & SIM & NÃO \\
\hline $\begin{array}{l}\text { Exigências de } \\
\text { produtividade? }\end{array}$ & $100 \%$ & $0 \%$ \\
$\begin{array}{l}\text { Existem movimentos } \\
\text { repetitivos? }\end{array}$ & $100 \%$ & $0 \%$ \\
$\begin{array}{l}\text { O trabalho exige posturas } \\
\text { forçadas dos membros } \\
\text { superiores }\end{array}$ & $87,5 \%$ & $12,5 \%$ \\
\hline
\end{tabular}

A análise da avaliação da organização do trabalho apresentou os seguintes resultados para cada um dos seus três itens acima mencionado na Tabela 1.

Ficou evidenciado em nossos achados unanimidade nas respostas referente às questões de exigências de produtividade e existência de movimentos repetitivos que sugerem a alta possibilidade de aparecimento de LER/DORT. Resultados estes que vão de encontro aos achados de [9] que em sua investigação verificaram que diversas categorias que tem em comum a repetitividade de movimentos e o esforço físico, são atingidas por LER/DORT, entre elas, os trabalhadores de preparação de alimentos, e também no estudo de [10], onde verificou-se que atividades onde existam sobrecarga muscular estática para manutenção da postura por períodos prolongados, excesso de força empregada na execução de tarefas, tornam-se fatores para o aparecimento das LER/DORT, corroborando com as evidencias do presente estudo.

Considerações críticas a este conjunto de explicações não negam a dimensão subjetiva presente na patologia, mas centralizam sua atenção na relação entre o trabalhador (o psicológico e o individual) e o contexto do trabalho. Além disso, a LER/DORT inclui afecções que tem sua origem, não em um agente externo, mas em uma ação, o que pressupõe o envolvimento de um sujeito que a executa. Assim é que, além da autoidentificação dos portadores como pessoas "elétricas", que trabalham em ritmo intenso, ou como "perfeccionista" e que assumem muitas atividades, é necessário considerar que tais características são sustentadas por uma ideologia de trabalho em que o máximo é uma atitude valorizada [10].

Tabela 2. Questões referentes a sobrecargas dos membros Inferiores no trabalho

\begin{tabular}{lrr}
\hline QUESTÕES & SIM & NÃO \\
\hline $\begin{array}{l}\text { Existe uma pausa natural entre o final de } \\
\text { um ciclo e o inicio do ciclo seguinte? }\end{array}$ & $25 \%$ & $75 \%$ \\
O trabalho é realizado em pé? & $100 \%$ & $0 \%$
\end{tabular}


A análise da avaliação da organização do trabalho apresentou os seguintes resultados para seus três itens da Tabela 2:

lida (1997) [13], quando analisa as posturas do corpo, explica que a posição parada, em pé, é altamente fatigante porque exige muito trabalho estático da musculatura envolvida para manter essa posição. O coração encontra maiores resistências para bombear sangue para os extremos do corpo. O mesmo autor, quando analisa trabalho estático, refere que "quando um músculo está contraído, há aumento na pressão interna, o que provoca um estrangulamento dos capilares. Isso acontece com facilidade, porque as paredes dos capilares são muito finas e a pressão sanguínea nos músculos é muito baixa.

Já Grandjean (1998) [14] ao analisar a postura de pé no local de trabalho transcreve que o "ficar de pé no local" exige um trabalho estático para imobilização prolongada das articulações dos pés, joelhos e quadris. Provoca aumento importante da pressão hidrostática do sangue nas veias das pernas e o progressivo acúmulo de líquidos tissulares nas extremidades inferiores, favorecendo a maior incidência de alargamento das veias das pernas (varizes) e "edemas dos tecidos dos pés e pernas".

De acordo com a NR 17.6.3 atividades que exijam sobrecarga muscular estática dos membros inferiores devem ser incluídas pausas para descanso.

De igual teor, é evidenciado que a LER/DORT não são frutos exclusivos de movimentos repetitivos, mas podem ocorrer pela permanência de segmentos do corpo em determinadas posições, por tempo prolongado, de acordo com a instituição normativa do Instituto Nacional de Seguridade social (INSS).

Afirmações essas que estão de acordo com os achados no presente estudo e vão de encontro aos dados encontrados nas 3 (três) perguntas da tabela 2. Na primeira pergunta ficaram evidenciados $25 \%$ de respostas afirmativas contra $75 \%$ de negativas para pausas durante o trabalho e na segunda e terceira respostas ficaram comprovados $100 \%$ de afirmações em relação ao trabalho realizado em pé e estático. Ainda em relação às posturas adotadas sugere-se o uso do banco semisentado, pois o mesmo reduz significativamente à sobrecarga nas articulações dos pés, joelhos e quadril, alivia a musculatura evitando fadiga e ainda diminui a tensão sobre a lombar evitando lombalgias e em relação às pausas durante a jornada de trabalho sugere-se que as mesmas passem a serem adotadas a critério do proprietário e que durante as mesmas os funcionários realizem o movimento de flexão plantar com o objetivo de auxiliar o retorno venoso melhorando a circulação e evitando problemas futuros.

\section{Aplicações práticas}


A partir de nossos achados fica evidenciado que um trabalho com a aplicação de um simples questionário foi capaz de diagnosticar os postos de trabalho de uma indústria alimentícia que podem sofrer maiores riscos de LER/DORT e propor intervenções para melhorias nas empresas.

\section{CONSIDERAÇÕES FINAIS}

Após o término da pesquisa não foi detectado nenhum trabalhador acometido por LER ou DORT, todavia a apresentação dos postos de trabalho e a organização do trabalho deixam muito a desejar.

Em relação aos postos de trabalho, fatores como posturas incorretas e mantidas, repetitividade de movimentos, trabalho realizado em pé e estático e movimentos forçados dos membros superiores são encontradas ao longo de toda a linha de produção, o que aumenta o risco de lesão e diminui o conforto durante a jornada de trabalho.

Já em relação ao sistema de trabalho, cobranças em relação à produção e falta de cobrança em ralação as atitudes corretas também estão diretamente ligadas as causas de lesões.

Como já explanado nas limitações do estudo, o pequeno número de participantes e pouco prazo de acompanhamento aos trabalhadores podem ter limitado os resultados desejados, entretanto, ainda assim, foi possível, através deste estudo, reconhecer que uma ginástica laboral na forma de alongamento em pequenas pausas em períodos de trabalho pré-determinado associada a algumas alterações no posto de trabalho, tal como, um banco semi-sentado para os funcionários, trazem benefícios preventivos no acometimento de LER/DORT.

Novas investigações devam surgir para que maiores fundamentações sustentem nossos achados no que tange LER/DORT em indústrias alimentícias. Amostras diferentes, maiores e afazeres distintos são opções para estudos futuros.

Findado este estudo, ficou comprovado a afirmação tantas vezes citada em estudos com os mesmos objetivos que "o trabalho que deve ser adaptado ao homem e não o homem ao trabalho".

\section{REFERÊNCIAS}

[1] IIDA, I. Ergonomia: projeto e produção, São Paulo, Edgard Blucher Ltda., 1990.

[2] Norma Regulamentadora 17, (Redação dada pela Portaria MTPS n. 3.751 , de 23 de novembro de 1990), NR 17.6.3-ERGONOMIA.

[3] Assunção, A. \& Rocha, L. (1995). Agora... até namorar fica difícil: Uma historia de lesões por esforços repetitivos. Em JT Buschinelli, L. Rocha \& R. Rigotto (Orgs.), Isto é trabalho de gente? (PP. 461-473). Petrópolis RJ: Vozes. 
[4] OLIVEIRA JRGO. A prática da ginástica laboral. 3ํㅡ. Ed. Rio de Janeiro: Sprint, 2006.

[5] Brasil. Ministério da Saúde. Representação no Brasil da OPAS/OMS. Doenças relacionadas ao trabalho: manual de procedimentos para serviços de saúde.

Brasília: Ministério da Saúde; 2001.

[6] Brasil. Ministério da Saúde. Secretaria de Ação a Saúde. Departamento de ações programáticas estratégicas. Lesões por esforços repetitivos (LER) distúrbios osteomusculares relacionados ao trabalho (DORT). Ministério da Saúde, Secretaria de Atenção a Saúde, Departamentos de Ações Programáticas. Brasília: Ministério da Saúde; 2005.

[7] Tuomi K, Ilmarinen J, Jahkol A, Katajarinne L, Yulkki A. Índice de Capacidade para o trabalho. Tradução de FM Fischer. Helsinki: Instituto de Saúde Ocupacional; 1996.

[8] Pereira ER. Fundamentos de ergonomia e fisioterapia do trabalho. Rio de Janeiro:

[9] Taba Cultural; 2001.

[10] VIIKARI-JUNTURA, E.; KURPPA, K.; KUOSMA, E.; HUUSKONEM, M.; KUORINKA, I.; KETOLA, R.; KÖNNI, U. Prevalence of epicondylitis and elbow pain in the meat-processing industry. Scand J Work Environ Health, 17:38-45, 1991.

[11] HELFENSTEIN Jr, Milton. Lesões por esforços repetitivos (LER/DORT): conceitos básicos. V. 1 e 3. São Paulo: Schering-plough,1998.

[12] Sato, L., Araújo, M., Udihara, M. L., Nicotera, F., Dalton, M.T., Settimi, M. \& Silvestre, M. (1993). Atividades em grupo com portadores de LER e achados sobre a dimensão psicossocial. Revista Brasileira de Saúde Ocupacional, 79(21), 49-62.

[13] RIO, R.P.LER - ciência e lei: Novos horizontes da saúde e do trabalho. Belo Horizonte: Health: 1998. 331 p.

[14] IIDA, I. 1997. Ergonomia: projeto e produção. São Paulo, Ed. Edgard Blücher. GRANDJEAN, E. 1998. Manual de Ergonomia: adaptando o trabalho ao homem. Tradução de João Pedro Stein. 4a. ed. Porto Alegre, Artes Médicas.

Recebido: 17 agosto 2017. Publicado: 17 outubro 2017

Correspondência: Josiane Aparecida Cardoso de Souza. E-mail: josisouzakta@hotmail.com

Conflito de Interesses: os autores declararam não haver conflito de interesses. 
(C) This is an Open Access article distributed under the terms of the Creative Commons Attribution License, which permits unrestricted use, distribution, and reproduction in any medium, provided the original work is properly cited 